\title{
Guest Editor's Introduction: Alternative Approaches in the Korean Archaeology
}

Yongwook Yoo*

"I don't need problems, I need a solution!" - Gen. Francis X. Hummel from the Motion Picture "The Rock (1996)"

Archaeology has played a significant role in reconstructing and formulating Korean prehistory and history since it emerged as a subdiscipline of history and anthropology in the early twentieth century. Due to its unique methodology of discovering material records and deciphering their meanings and context, archaeology has identified itself either as a pure classical humanities approach or a new scientific approach to the past. In either case, the glaring deficiency in Korean archaeology is lack of dialogue among researchers. As a modern independent discipline distinguished from conventional historiographic research, Korean archaeology should be devoid of positivistic claims because actors and actions of the past are not to be clearly imprinted on the material data or artifact assemblages, archaeologically. With actors and actions unclarified, the narrative can't be constituted; archaeological knowledge and its descriptive phrases always tend to be segmentary because past events cannot but be restored as "ownerless."

* Professor, Department of Archaeology, Chungnam National University, Daejeon, S. Korea 
Korean archaeology has been strongly dependent on the framework of culture-oriented statements. The term "(archaeological) culture" here is a concept devised by European archaeologists in the early twentieth century and was imported by modernists, mostly Japanese imperial colonists, at the dawn of Korean archaeology. Since then, because there is no way of determining the actors by decoding human behavior from artifact data, the concept of culture has become treated as past human behavior in its totality at a specific place and time. The goal of Korean archaeology has thus become the identification and comparison of many archaeological culture(s) as possible and a well-defined archaeological culture always has been the unit and subject for describing Korean past events, especially for prehistoric times when no written record was available. The local archaeological culture is readily regarded as identical to the real people or racial group of the past; the diversity among artifact assemblages is always believed to be ethnic or local variation; similarity between geographically separated assemblages reflects either migration or diffusion conducted by ethnic groups of the same origin.

Even though archaeological culture has been an effective research tool for the last several decades, the limitations of this concept are numerous. Above all, the existence of culture seems to be far from reality in artifact assemblages since it cannot be objectively measured and quantified. Everybody can discern the similarities and differences of artifact assemblages but this does not indicate the extent to which past people conveyed and diversified human culture reflected on the material record. In particular, when we witness similarity/difference among artifact assemblages, we cannot find acceptable explanations as to how these characteristics came to exist and why they were transformed in that way. The culture is totally made out of human interactions against nature among human groups but we cannot adequately answer the questions on "how" and "why," depending on the description of artifact assemblages using such an unrealistic concept of archaeological culture. Should Korean archaeology take the form of ordinary science putting emphasis on hypothesizing and solving problems, the result of archaeological research always tends to turn up 
questions rather than answers because there is no genuine way to build plausible narratives combining actors, behaviors, and events using this stereotyped culture concept. It is well-known that modern archaeology has tried to become a scientific way of describing the past in the context of human behaviors; but Korean archaeology failed to and never intended to be scientific since it did not involve the positivistic perspective on how past humans actively coped with their lives and why they left such a data set available to current archaeologists.

Unlike normal history, archaeology has a crystal-clear academic advantage: it has an abundant supply of diverse material records. The amount and rate of this supply is quite impressive; we can have huge sets of artifacts from a single site and need to decode meanings and values of these artifacts; we can squeeze out some implicative ideas from these data; we can expect some more detailed information from the next set of data. In this series of data supply, however, there are some positive and negative feedback and we can arrive at an impasse of ideas on the past; there is always some form of a logical stalemate and sometimes problemsolving does not work with the limitations of current thinking and data sets. I cannot exactly pinpoint the cause of the current logical stalemate of Korean archaeology but I can clearly point to some prerequisites for a breakthrough. As a common archaeologist in Korea, I have been always yearning for a better way of understanding the past. Not only understanding the past itself but also setting an alternative agenda for understanding is a critically important task in Korean archaeology. A quantum-leap in archaeological thinking is not a usually witnessed phenomenon but can be ultimately realized by a simple but pesky research attitude-openmindedness for alternative approaches.

The special topic of this issue is an initial endeavor for a better understanding of the Korean past with some alternative approaches to the deeply rooted culture-oriented framework. Taking alternative positions always involves the awareness of limitations and the problems of current research paradigms. The three articles presented here share a common belief that a complacent attitude on the academic accomplishments of Korean archae- 
ology no longer guarantees better understandings of the Korean past. They critically review past data sets and classic notions anchored in the Korean archaeological academy; they demonstrate new data and evaluate them with the purpose of setting a new research agenda. Their primary goal is not to argue with new synthesis but to establish an alternative position which can be modified, disputed, and even discarded later by other new alternatives. Yongwook Yoo (유용욱) coins the term "Pleistocene Modernity" and discusses the issue of the emergence of the modern human species and its archaeological evidence in Korea. Junkyu Kim (김준 규) covers the problem of territory expansion in the course of ancient kingdom development. His case study on the geographical expansion of Paekche (百濟) includes a well-balanced theoretical consideration of the sequential occupation model that can be globally applied and substantiated with current archaeological data. Hyunwoo Kim (김현우) deals with an unprecedented issue of “Medieval Archaeology (中世考古學)" in Korea. As a starting point of new tasks and themes in Korean archaeology, this article furnishes a good initiative to narrate a more vivid version of Koryŏ and Chosŏn history (高麗·朝鮮史).

These three articles are not self-contained knowledge; they should yield to new critical approaches prepared by other researchers now. In the meantime, however, their positions and perspectives are worth examining since they can be examples of welcoming alternatives in Korean archaeology which is no longer obsessed with such outdated frameworks as the concept of archaeological culture and its space-time distribution. Of course, a new series of archaeological data supply should be ensured so that they will contribute to the ongoing process of developing new alternatives in the future. 